\title{
Foreign body aspiration during dental treatment under general anesthesia: A case report
}

\author{
Re-Mee Doh \\ Department of Advanced General Dentistry, School of Dentistry, Dankook University, Cheonan, Korea
}

\begin{abstract}
Foreign body aspiration in dental clinics is the most common cause of respiratory emergencies. There are no reports on foreign body aspiration during dental treatment under stable general anesthesia because the patient neither has voluntary movements nor reflex actions. This is a case report on the fall of a prosthesis in the larynx, which occurs rarely under general anesthesia. During the try-in procedure, the prosthesis slid from the surgeon's hand and entered the retromylohyoid space, and while searching for it, it passed down the larynx to the endotracheal tube balloon, leading to a dangerous situation. The prosthesis was promptly removed using video-assisted laryngoscope and forceps, and the patient was discharged without any complications.
\end{abstract}

Keywords: Aspiration; Foreign bodies; General Anesthesia.

This is an Open Access article distributed under the terms of the Creative Commons Attribution Non-Commercial License (http://creativecommons.org/licenses/by-nc/4.0/) which permits unrestricted non-commercial use, distribution, and reproduction in any medium, provided the original work is properly cited.

\section{INTRODUCTION}

Foreign body aspiration is the most common respiratory emergency in dental clinics, because dental treatments use small instruments and materials in the oral cavity, which may deteriorate the patient's reflex mechanism [1]. The treatment method depends on whether the foreign body has moved to the gastrointestinal or respiratory tract and whether it could potentially damage the gastrointestinal tract or respiratory mucosa. Aspired foreign bodies are mostly found in the right main bronchus because of its smaller angle and larger diameter compared the left main bronchus. Half the patients with foreign body inhalation and over $90 \%$ with foreign body ingestion are asymptomatic and may be unaware that an inhalation or ingestion has occurred [2]. anesthesia for dental treatments are rare. Accidental foreign body ingestion has been reported in patients before waking from anesthesia, when the lung function has not fully recovered [3]. No aspiration cases during dental treatments under stable general anesthesia have been reported because these treatments allow neither voluntary movements nor reflex actions. General anesthesia using anesthetic gases and muscle relaxants stops all swallowing and reflex functions, and the patient is subjected to artificial respiration. After complete anesthesia, swallowing is stopped, and aspiration is unlikely because of physical barriers, such as tongue, packing, and endotracheal tube. This is a case report on the fall of a prosthesis in the larynx, which occurs rarely under general anesthesia.

Reports on foreign body aspiration during general

Received: March 25, 2019 • Revised: April 18, 2019 - Accepted: April 20, 2019

Corresponding Author: Re-mee Doh, Department of Advanced General Dentistry, School of Dentistry, Dankook University, 119 Dandae-ro, Dongnam-gu, Cheonan-si,

Chungnam, 31116, Korea

Tel: +82-41-550821 Fax: +82-41-5500117 E-mail: remeedoh@dankook.ac.kr

Copyright(c) 2019 Journal of Dental Anesthesia and Pain Medicine 


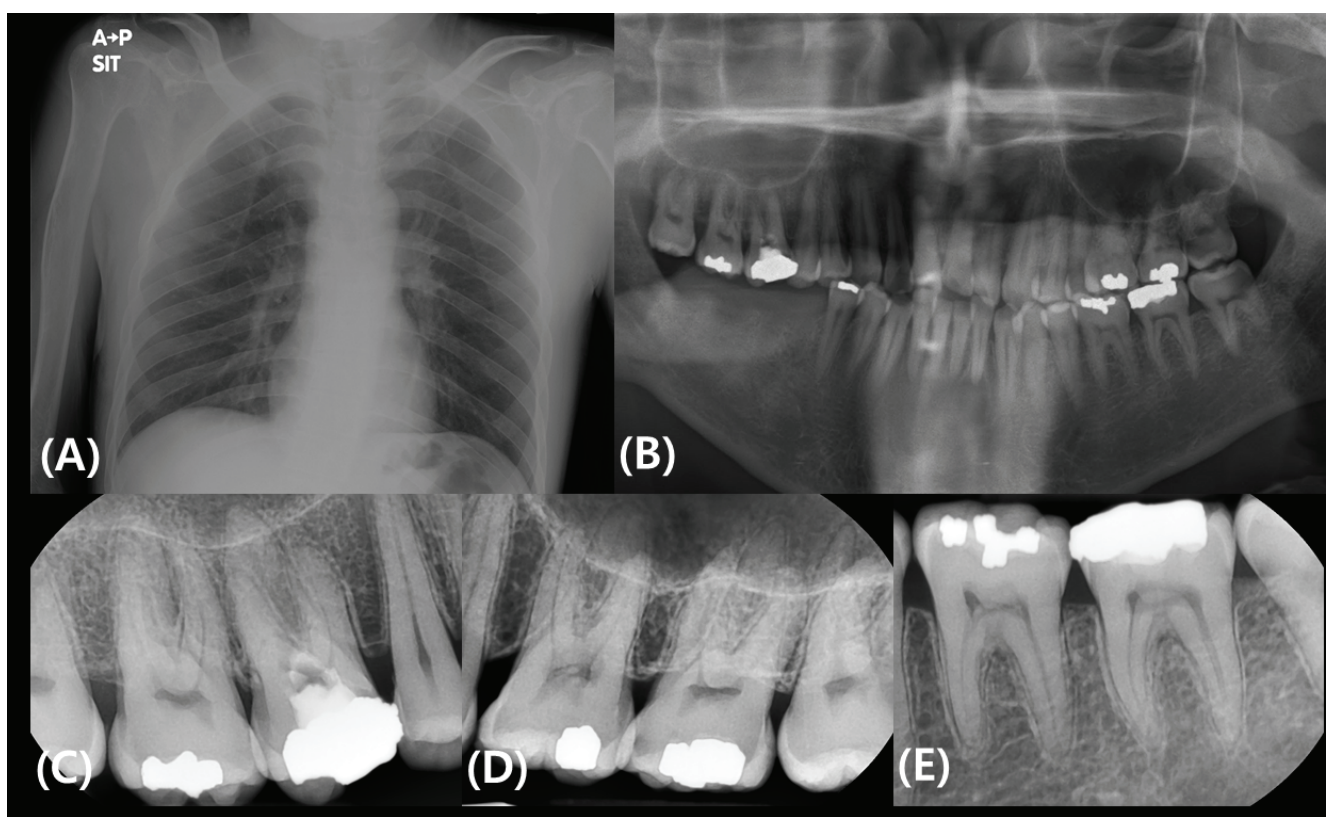

Fig. 1. A posteroanterior (PA) chest and dental radiographs of the patient. (A) Chest PA obtained before surgery showed normal findings. (B-E) Panoramic view and intraoral radiographs of the patient at first operation day.

Table 1. Treatment procedures under general anesthesia

\begin{tabular}{|c|c|c|c|c|}
\hline & Anesthesia time & Operation time & Anesthesia note & Dental procedures \\
\hline $\mathrm{G} / \mathrm{A}$ & $265 \min$ & $195 \min$ & $\begin{array}{l}\text { 1) } 4 \mathrm{~L} / \text { min } \mathrm{O}_{2}, \mathrm{~N}_{2} \mathrm{O} \text { via } \\
\text { mask } \\
\text { 2) } 4 \% \text { sevoflurane } 2 \\
\mathrm{~L} / \text { min for } 3 \text { min } \\
\text { 3) nasal intubation } \\
\text { (size\#6.5, right, } 26\end{array}$ & $\begin{array}{l}\text { 1) Scaling } \\
\text { 2) Class I and II direct composite filling } \\
\text { of teeth 17, 15, 14, 12, 22, 25, 34, 36, 44, and } 45 \\
\text { 3) Class IV composite filling (incisal edge) of teeth } 11 \text { and } 21 \\
\text { 4) Preparation and final impression for ceramic and gold inlay of teeth } \\
24 \text { (M), } 26 \text { (MOD), and } 27 \text { (M0) } \\
\text { 5) Core, preparation, final impression and provision of gold crowns for } \\
\text { teeth } 16 \text { and } 37\end{array}$ \\
\hline $\mathrm{G} / \mathrm{A}$ & $155 \min$ & $110 \min$ & $\begin{array}{l}\text { 4) } 2 \% \text { sevoflurane } \\
\text { (during operation) }\end{array}$ & $\begin{array}{l}\text { 1) Try-in and delivery of } 16 \text { and } 37 \text { gold crowns } \\
\text { 2) Try-in and delivery of } 24 \text { ceramic inlay and } 26 \text { and } 27 \text { gold inlays } \\
\text { 3) RMGI filling in teeth } 28 \text { and } 36 \\
\text { 4) Amalgam filling in teeth } 28 \text { and } 38 \\
\text { 5) Simple extraction of tooth } 18\end{array}$ \\
\hline
\end{tabular}

G/A: general anesthesia, M: Mesial, MO: Mesial-occlusal, MOD: Mesial-occlusal-distal, RMGl: Resin-modified glass ionomer

\section{CASE REPORT}

A 36-year-old man visited the dental hospital for treatment of decayed teeth. He had Wilson's disease, which causes impaired copper metabolism. He was able to communicate with people but had mental retardation and extreme fear and anxiety toward dental treatment. $\mathrm{He}$ took Altamin and anticonvulsants once a day. His weight was $60 \mathrm{~kg}$, and his general condition was normal. The posteroanterior chest radiograph revealed no abnormal findings (Fig. 1A). Intraoral clinical and radiographic examinations revealed generalized gingivitis and multiple moderate-to-advanced dental caries (Fig. 1B-E). The patient needed multiple operative, periodontal, and prosthodontic treatments. After general examination, two minimal visits of dental treatment using general anesthesia were planned. Before the surgery, he underwent blood tests, chest radiography, and risk assessments. Written informed consent for the planned procedures were obtained from him and his guardian. 

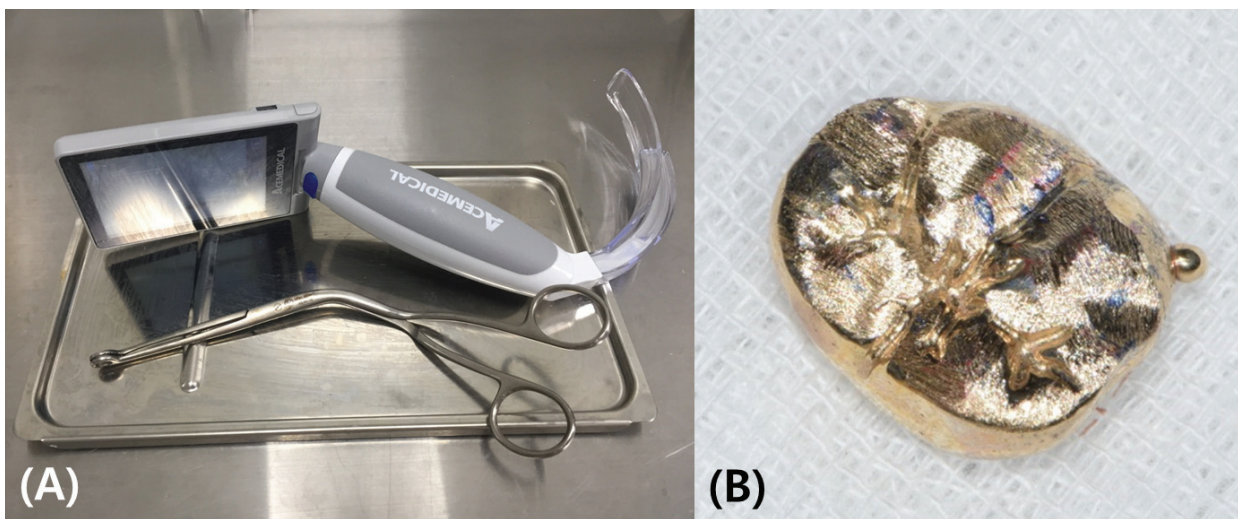

Fig. 2. (A) Video laryngoscopy with touch screen (AceScope, Acemedical Co., Seoul, Korea) and curvilinear forceps. (B) The gold crown of tooth 36 found inside the neck.

\section{Procedures}

The patient was instructed to maintain his routine medication. His electrocardiography, heart rate, blood pressure, respiratory rate, end-tidal capnography, body temperature, and entropy levels were monitored during the procedures. An intravenous (IV) line was secured under $4 \mathrm{~L} / \mathrm{min}$ of $\mathrm{O}_{2}$ and $\mathrm{N}_{2} \mathrm{O}$ gases (administered via a face mask), and $4 \%$ sevoflurane gas and atracurium (IV $25 \mathrm{mg}$ ) were also administered. Under an adequate depth of anesthesia, the epiglottis was examined with a bronchoscope and an oral camera, and gentle intubation using a Mac size\#3 laryngoscope was performed. The trachea was successfully intubated with a $26-\mathrm{mm}$ endotracheal tube (ETT), without bleeding. Anesthesia was maintained with $2 \mathrm{~L} / \mathrm{min}$ of $\mathrm{O}_{2}$ and $\mathrm{N}_{2} \mathrm{O}$ and $2 \%$ sevoflurane. The entropy level was recorded every 10 minutes. In both the general anesthesia, response entropy (RE) was maintained in the range of 35-54 and state entropy (SE) of 30-45 during the procedure. No specific events occurred (Table 1).

At the first visit, scaling, composite filling of tooth 12 , and preparation and final impression for indirect inlay were performed under general anesthesia, and crown preparation, final impression, and provision of gold crowns for teeth 16 and 37 were achieved. At the second visit, the delivery of five prosthetic teeth $(16,24,26,27$, and 37), simple extraction of tooth 18 , and treatment of some caries were done.

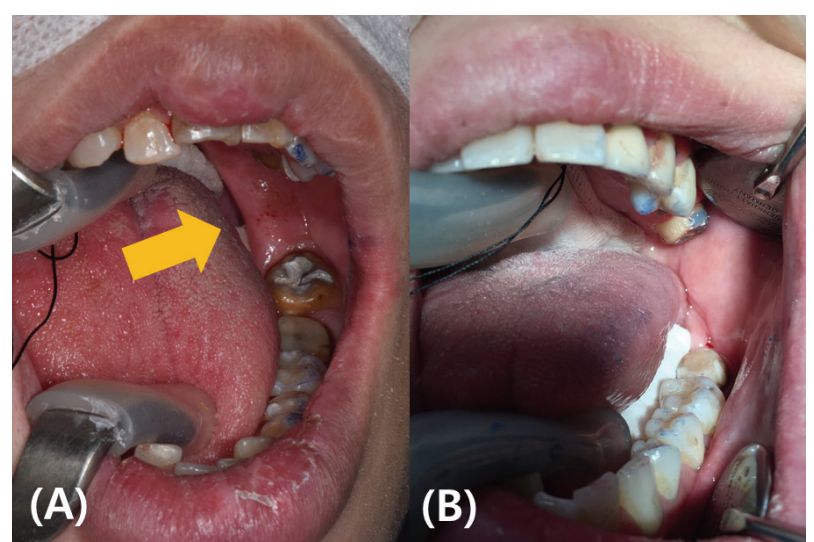

Fig. 3. Intraoral photographs of patients with oropharyngeal pack. (A) The patient of this case report. The arrows indicate the gap between the oropharyngeal pack and the tongue. (B) Another patient in a similar situation. The tongue and an oropharyngeal pack are completely closed between the mouth and the pharynx.

During the try-in step, the gold crown for tooth 36 slid from the surgeon's hand. The prosthesis was found neither on oral examination nor in the operation room. In a subsequent oral examination, when the tongue was tilted, the crown was found near the endotracheal tube balloon. The prosthesis was promptly removed using video-assisted laryngoscopy and curvilinear forceps (Fig. 2). Subsequently, dental floss-tied gauze packing was performed to prevent recurrence of the accident. After $2 \mathrm{~h}$ and $35 \mathrm{~min}$ from the treatment, the patient recovered upon $100 \%$ oxygen administration. During the procedure, the patient exhibited no specific complications. He was discharged 1 hour after stabilization. 


\section{DISCUSSION}

During dental treatment under general anesthesia, various foreign substances (tooth fragments, old restoration pieces, bur, filling material, implant components) are introduced in the oral cavity. If these foreign substances enter the airways, there is a high risk of inhalation in the respiratory tract, causing pneumonia during tube removal after the anesthesia recovery. To prevent such accidents, the rubber dam isolation method should be used for restorative and root canal treatments and oropharyngeal packs (packing gauze) for other surgical and prosthetic treatments [4,5]. However, packing gauzes could interfere with the dental treatment in patients with an enlarged tongue. Despite gauze packing, gaps may remain because of the tongue position (Fig. 3). The patient in this case had an enlarged tongue. To reduce tongue interference during the occlusal adjustment of the prosthesis, the packing gauze was temporarily removed, which made the prosthesis fall inside the neck.

As the patient's voluntary motions and reflex actions were stopped, the molar prosthesis was expected to be easily visible over the tongue. However, in this case, the prosthesis was not found in the oral cavity, as it entered the retromylohyoid space, which is located below and behind the mylohyoid ridge and represents the S-curve of the mandible, usually covered by the tongue. However, when the tongue was laterally displaced for occlusion, the prosthesis fell in the gap between the tongue and the mandible and was difficult to find. In an attempt to find it, the surgeon moved the tongue from one side to another, causing the prosthesis to fall in the retromylohyoid space, down to the larynx. The missing prosthesis was found caught in the endotracheal tube because of its round and bulky shape. However, if the foreign body is a fractured sharp tip or a small diamond bur, it is difficult for the surgeon to find it. Preventing the foreign body from reaching the larynx is of utmost importance. Therefore, small-size gauze packing must be performed in specific procedures such as try-in of prostheses, and gauze should be bundled with black silk or dental floss for easy removal. In addition, video-assisted laryngoscopy can be used to remove foreign substances more rapidly and accurately in cases of narrow throat and poor visibility [6]

Davis et al. reported on reducing the possibility of aspiration by coating oral cavity with radiopaque material in children undergoing general anesthesia [7]. Studies have shown that blood, saliva, and pus touch the throat tissue even with a well-placed oropharyngeal pack. To prevent this, the wet packing should be frequently replaced during the treatment and suction should be used in the oral cavity.

\section{AUHOR ORCIDS}

Re-Mee Doh: https://orcid.org/0000-0001-8512-9134

CONFLICTS OF INTEREST: The authors have no conflicts of interest to declare.

\section{REFERENCES}

1. Park WS, Kim ST, Park MS, Seo JS, Kim KD. Foreign Body Asporation in Dental clinic - Case Series. J Korean Dent Soc Anesthesiol 2011; 11: 38-44.

2. Hou R, Zhou H, Hu K, Ding Y, Yang X, Xu G, et al. Thorough documentation of the accidental aspiration and ingestion of foreign objects during dental procedure is necessary: review and analysis of 617 cases. Head Face Med 2016; 12: 23.

3. Kim KN, Kim KS, Lee HJ, Oh YN. Accidental ingestion of a fixed partial denture during general anesthesia - A case report. Anesth Pain Med 2015; 10: 138-40

4. Fields RT, Jr., Schow SR. Aspiration and ingestion of foreign bodies in oral and maxillofacial surgery: a review of the literature and report of five cases. J Oral Maxillofac Surg 1998; 56: 1091-8.

5. Pingarron Martin L, Moran Soto MJ, Sanchez Burgos R, 
Burgueno Garcia M. Bronchial impaction of an implant screwdriver after accidental aspiration: report of a case and revision of the literature. Oral Maxillofac Surg 2010; 14: $43-7$.

6. Hidaka H, Suzuki T, Toyama H, Kurosawa S, Nomura K, Katori Y. Dislocated dental bridge covering the larynx: usefulness of tracheal tube guides under video-assisted laryngoscopy for induction of general anesthesia, thus avoiding tracheostomy. Head Face Med 2014; 10: 23.

7. Davis J, Anaes FC, Alton H, Butler J. Aspiration of foreign materials in children while under general anesthesia for dental extractions. Anesth Pain Control Dent 1993; 2: $17-21$. 